\title{
Las Relaciones Personales y Literarias entre Darío y Unamuno
}

Tna revista norteamericana de gran circulación en Hispanoamérica publicó hace poco cierta referencia del "incidente" entre Rubén Darío y Miguel de Unamuno, que El Universal, diario de México, reprodujo en los siguientes términos:

"Cuenta Valle-Inclán que Rubén Darío había escrito una crónica en elogio de Unamuno que iba a enviar a 'La Nación', de Buenos Aires, cuando alguien le mostró un artículo del mismo Unamuno, que decía: 'Rubén Darío llevaba en la cabeza las plumas de salvaje que le sirven para escribir.' Darío se encogió de hombros y exclamó: 'Bien, ésa es la opinión de él.' $Y$ a continuación envió a Unamuno, con el artículo, una carta en que le decía: 'Este artículo fué escrito con las plumas de salvaje que llevo en la cabeza, y no tengo nada que rectificar de él.'

"Unamuno me dijo a mí, tiempo después -comentaba Valle-Inclán- que nunca cosa alguna le había desconcertado tanto como aquella carta de Rubén." (El Universal, "Anécdotas y filosofía barata", 28 de septiembre, 1943.)

Esta referencia no es rigurosamente exacta, aunque son ciertos los dos hechos fundamentales: que Unamuno profirió una frase mordaz sobre Darío y que el gran poeta de Hispanoamérica dirigió con tal motivo al gran escritor español una carta ejemplar. Hay en la anécdota - como anécdota se cuenta y así se ha divulgado entre el gran público de habla española de este continente- algunos errores históricos, que deben ser rectificados por cuanto se trata de figuras de la más alta calidad en las letras hispánicas. Saliendo por los fueros de la verdad, me creo en el deber de publicar el presente artículo movi- 
do por la devoción literaria que profeso a ambos escritores y por la amistad personal que con ellos me unió.

Desde que en 1919, con motivo de una visita que hice a la Universidad de Salamanca, conocí a su ilustre rector, tuve siempre con don Miguel de Unamuno afectuosa relación. Sigo consagrándole admiración profunda. Por lo que respecta a Rubén Darío, mi estrecha amistad con Santiago Rusiñol -gloria de las letras catalanas y pintor eximio de los jardines de España - me llevó al círculo de los anigos intimos del excelso poeta, cuando éste, víctima de acelerada decadencia física y mental, fué a Barcelona por última vez en 1914. Ya el águila no podía volar por entre las altas cumbres, y casi le era imposible sostenerse al nivel de los campanarios. Quienes de veras estimábamos al escritor y al hombre, procuramos hacer por él, con delicadeza fraternal, lo que dado su difícil carácter en aquellos días era posible. Yo le recuerdo con efusión cordial siempre que vuelvo a leer sus obras, y quiero rendirle al escribir estas líneas un nuevo tributo de sincera amistad examinando, a través de mis impresiones personales y de las cartas de ambos escritores, la índole de las relaciones que mediaron entre Rubén Darío y Miguel de Unamuno.

Procede, en primer término, restablecer la verdad en cuanto a la referencia del "incidente de las plumas del indio". Yo no sé sì la relación anecdótica está basada en algún texto de Valle-Inclán. "Este gran don Ramón de las barbas de chivo" - - como le dijo Rubén Darío en el primer verso de su conocido soneto-, el maravilloso estilista de las Sonatas y de tantos bellos libros, merecía escaso crédito en sus relatos, subordinados siempre al propósito de producir determinados efectos, por cualquier medio, en el auditorio o en los lectores. Yo lo he oído contar - en su famosa tertulia del Ateneo de Madrid- con tres o cuatro referencias absolutamente distintas, a cual más pintoresca, el personal y doloroso episodio de la pérdida de su brazo. No le parecía "literario" que hubiera sido preciso amputárselo por consecuencia de un mal golpe recibido de cierto escritor villano.

En el caso de que estoy tratando, el supuesto testimonio de Valle-Inclán no refleja la verđad. Es inexacto que Unamuno haya hecho públicos en un artículo juicios desfavorables para Darío. $Y$ es absolutamente falso que escribiera la frase que en la anécdota se le atribuye. Habría sido una estupidez impropia de él. Dijo - en con- 
versación entre gente de letras- algo semejante, y ello fué una torpeza y una injusticia de las que siempre estuvo arrepentido y sinceramente apenado.

El propio Unamuno toma el lamentable episodio como tema del emocionado artículo que escribió al morir Darío con el título: "Hay que ser justo y bueno, Rubén." Esta invocación a la justicia y a la bondad se la dirige a sí mismo, no al poeta. $Y$ dice en uno de los primeros párrafos: "Con esta lengua que el Demonio nos ha dado a los hombres de letras, dije una vez delante de un compañero de pluma, que a Rubén se le veían las plumas - las del indio- debajo del sombrero; y el que me lo oyó, ni corto ni perezoso, esparció la especie, que llegó a oídos de Darío."

"Esta es la verdad. Efectivamente, con fecha 5 de septiembre de 1907, Rubén Darío dirigió a Unamuno, desde París, una carta que comienza así: "Mi querido amigo: Ante todo, para una alusión. Es con una pluma que me quito debajo del sombrero con la que le escribo. $Y$ lo primero que hago es quejarme de no haber recibido su último libro. Podrá haber diferencias mentales entre usted y yo, pero jamás se dirá que no reconozco en usted - sobre todo después de haberle leído en estos últimos tiempos- a una de las fuerzas mentales que existen hoy, no en España, sino en el mundo." $Y$ termina con estos dos párrafos: "La independencia y la severidad de su modo de ser le anuncian para la justicia. Sobrio y aislado en su felicidad familiar, debe comprender a los que no tienen tales ventajas"... "Usted es un espíritu director. Sts preocupaciones sobre los asuntos eternos y definitivos le obligan a la justicia y a la bondad. Sea, pues, justo y bueno"... "Ex toto corde, Rubén Darío."

La frase final de esta magnífica carta, "Sea, pues, justo y bueno", debió llegar al corazón de Unamuno, y el eco de su sentimiento vibra en el artículo necrológico. Uno y otro escrito, plenos de sinceridad y de emoción, honran a sus respectivos autores. El ofendido, que se queja diciendo solamente: "Mas yo quisiera también de su parte alguna palabra de benevolencia para mis esfuerzos de cultura", y al ofensor, que se confiesa escribiendo: "iNo, no fú justo ni bueno con Rubén; no lo fuí! No lo he sido acaso con otros. Y él, Rubén, era justo y era bueno."

La actitud moral de Dario aparece así mucho más elevada que en la supuesta referencia de Valle-Inclán, donde con un artículo encomiástico para Unamuno, destinado a La Nación, se pretende con- 
ferir al poeta agraviado tuna farisaica superioridad. Hay también en este dato un error grande. El artículo a que se alude fué escrito año y medio después del "incidente". En otra carta de Rubén Dario, dirigida al rector de la Universidad de Salamanca con fecha 5 de abril de 1909, le dice entre otras cosas: "Hace algunos días envié a La Nación un trabajo, 'Unamuno, poeta', que le leí al amigo Manuel Machado y a quien le gustó mucho." Por entonces Darío había olvidado ya completamente la impertinencia de "las plumas del indio".

Rectificado así lo anecdótico, que por haberse publicado en una revista escrita en lengua española reprodujeron varios periódicos de Hispanoamérica de igtral modo que el más importante de los diarios de la ciudad de México, me propongo analizar la índole de las relaciones personales y literarias entre estos dos hombres a quienes la muerte abrió ya las puertas de la historia.

¿Fueron amigos, verdaderamente, Darío y Unamuno, con estimación sincera y recíproca? ¿Qué concepto tenía cađa uno de ellos de la personalidad, de la valía intelectual y. de la obra literaria del otro? Voy a examinar estos interesantes aspectos de sus relaciones personales y literarias.

No puedo aportar sobre ellos testimonio personal y directo. Cuando yo traté a Darío, se hallaba en tal estado de timidez frente a los problemas de la vida, que rehuía sistemáticamente emitir juicios sobre escritores españoles o hispanoamericanos, temiendo sin duda rozar amistades o intereses literarios y promover reacciones que pudieran perjudicarle. Con Unamuno nunca hablé de Dario, predominando en nuestras largas conversaciones los temas filosóficos y políticos.

Pero cabe utilizar textos auténticos. De Darío tenemos un artículo -el que publicó en La Nación, de Buenos Aires, con el título de "Unamuno, poeta" - y varias cartas que a éste dirigió. De Unamuno, el artículo necrológico sobre Rubén, ya citado, y largas epístolas de carácter personal y literario enviadas a Darío.

La correspondencia que entre ellos medió es ya una prueba de amistad y consideración. Unamuno no hubiera escrito tales cartas, seguramente de su puño y letra, a persona poco estimada. Darío, menos rígido en el desarrollo de sus relaciones personales, nunca dejó de ser hombre sincero cuando cré́a pisar terreno firme.

Escribe Darío a Unamuno en carta de 21 de mayo de 1899: " $\mathrm{La}$ innegable indigencia mental de nuestra patria, nos ha hecho 
apartar los ojos de ella; no es por culpa nuestra. Cuando hay algo que surge nuevo y vigoroso, lo ponemos sobre nuestra cabeza, sin vacilar. Vea cómo están apareciendo para América usted y Rusiñol, por ejemplo. La cultura, mucha o poca, nuestra es y ha de ser cosmopolita." Se hallaba Darío entonces en un período antiespañolista, pero salvaba de su desdén a Unamuno y también a Santiago Rusiñol, por quien tuvo siempre gran devoción.

Unos meses después, con fecha 14 de septiembre, se refiere a la labor académica del rector de la Universidad de Salamanca en estos términos: "En mi carta anterior a La Nación, y en la que debe salir el sábado, trato de la campaña universitaria que usted con tanto vigor ha emprendido. Me parece de un altísimo interés, y hago notar que allá puede sacarse provecho de las ideas de usted. Allá también se ha tratado mucho de la cuestión de la enseñanza, y su palabra autorizada ha de tener un eco seguro." $Y$ poco después le dice en otra carta: "Todavía no puedo pensar en un viaje a Salamanca. Pero la idea de hacerle una visita y estudiarle de cerca no me abandona. Me complace que en América se le haga justicia y le quieran como su aftmo. amigo..."

En 9 de enero de 1904, desde París, donde Darío tenía a su cargo el Consulado de Nicaragua, le escribe: "Veo que sus compatriotas de Buenos Aires no le perdonan sus conceptos contra el vascuence. Quizá no le han comprendido muy bien el hermoso discurso de los Juegos Florales"... "No pierdo la esperanza de volver a dar una vuelta por España y hacerle una visita en Salamanca."

De la carta de 5 de septiembre de 1907, motivada por el "incidente de las plumas del indio", ya transcribí algunos párrafos. Hay en ella otras expresiones muy interesantes: "Y luego, yo' soy uno de los pocos que han visto en usted al poeta. Que le ofrezcan a usted del sabio y del profesor, no me extraña. Su función universitaria le hace acreedor a ello, y nunca es de desdeñar una mayor cantidad de ciencia. Mas ¿quién ha de ver en un hombre tal el dón de la poesía sino los poetas ?" La respuesta de Unamuno a esta carta debió ser satisfactoria para Darío, porque en 3 de octubre siguiente le escribe: "Mucho me satisfizo su gentil carta de 26 del pasado. Creo que con quince días pasados con usted estaríamos completamente de acuerdo en todo. Esto no lo puedo realizar por ahora. Estoy a partir, de un momento a otro, para Nicaragua." 
Todavía encontramos dos cartas más en el Epistolario (volumen xini de las Obras completas de Rubén Darío, publicadas por Alberto Ghiraldo). En la de 17 de junio de 1908, desde Madrid, le dice a Unamuno: "En medio de un maremagnum de ocupaciones y de molestias, he logrado leer su último libro, que me ha encantado, por la sinceridad de espiritu, en usted habitual, y por la manera llana y clara de decir las cosas." $Y$ en la de 5 de abril de 1909 - era entonces Darío ministro de Nicaragua en España- se lee: "Es casi seguro que dentro de poco le haga la prometida visita."

La correspondencia duró, pues, por lo menos, según las cartas de este Epistolario, desde abril de 1899 hasta igual mes de 1909. Tengo noticia de que Ghiraldo ha publicado recientemente un libro más extenso que contiene mayor número de documentos del archivo particular de Rubén Darío; pero todavía no he podido consultarlo.

En el bello artículo "Unamuno, poeta", enviado por Darío al diario La Nación, de Buenos Aires (recogido en el volumen xv de las Obras completas), encontramos muy interesantes juicios sobre la poesía, los poetas y Unamuno. He aquí algunos de los que a éste se refieren: "Ciertamente, Unamuno es amigo de las paradojas $-y$ yo mismo he sido víctima de algunas de ellas-; pero es uno de los más notables renovadores de ideas que haya hoy, y, como he dicho, según mi modo de sentir, un poeta. Sí, poeta es asomarse a las puertas del misterio y volver de él con una vislumbre de lo desconocido en los ojos. Y pocos como ese vasco meten su alma en lo más hondo del corazón de la vida y de la muerte" ... "En Unamuno se ve la necesidad que urge al alma del verdadero poeta, de expresarse rítmicamente, de decir sus pensares y sentires de modo musical. $Y$ en esto hay diferentes maneras, según las dotes líricas del individuo; y no porque una música no se parezca a la del autor por vosotros preferido, hemos de concluir que no es buena. No todas las aves tienen el mismo canto, como todas las flores no tienen la misma forma ni el mismo perfume"... "Yo no he visto escribir versos al Rector de la Universidad de Salamanca, ni conozco su método de trabajo, ni sus bregas con el pensamiento y con el verbo. Pienso, sin embargo, que debe escribir con facilidad, pues las teorias de estrofas, en su ordenación que parece forzada, marchan holgadamente en la procesión poemática"... "Unamuno sabe bien que el verso, por la virtud demiúrgica, tiene algo de nuestra alma al salir de ella, que es tno de los grandes misterios del espíritu, que es un rito mortal para el cual 
la iniciación viene de una voluntad divina"... "Con ser muy castellano su vocabulario y muy castizo su misticismo le encontramos. cierto aire nórdico, que hace, a veces, que algunos de sus poemas parezcan traducidos de poetas de ojos azules"... "Malignamente, aquí donde es habitual jugar con el vocablo, he oído decir que los versos de Unamuno, como él quiere, son pesados. También el hierro y el oro lo son"... "De modo, me diréis, que Unamuno es, según su. opinión, un poeta. Un poeta, un fuerte poeta. Sil misma técnica es de mi agrado. Para expresarse así hay que saber mucha armonía y mucho contrapunto" .. Y $Y$ termina con estas palabras: "El canto quizá duro de Unamuno me place tras la meliflua lira que acabo de escuchar, que todavía no acabo de escuchar. $\mathrm{Y}$ ciertos versos que suenan como martillazos, me hacen pensar en el buen obrero del pensamiento que, con la fragua encendida, el pecho desnudo y transparente el alma, lanza su himno, o su plegaria, al amanecer, a buscar a Dios en lo infinito."

Tales son los juicios de Dario sobre la labor poética de Unamuno. Le reconoce una alta calidad de poeta. Y nótese lo que esto significa. La vida de Darío fué una serie de fracasos dolorosos en todas sus actividades, menos en una: la Poesía. Triunfó únicamente en ser poeta, excelso poeta, cuando escribía en verso o en prosa. Pero no fué más que poeta, aunque hubiera querido tener éxito en esas otras muchas cosas que suelen estar al alcance de los seres humanos más modestos. El tenía conciencia de su calidad de poeta, y el discernírsela también a Unamuno le otorgaba la prueba más grande de su estimación. Reconocer que el rector de la Universidad de Salamanca era un gran maestro, un filósofo, un ensayista, un poligrafo, o un escritor, no tenía importancia para Rubén. Reconocer que era poeta, "un fuerte poeta", como él, eso sí significaba mucho para Darío. E1 propio Rubén lo da a entender cuando en su carta de 5 de septiembre de 1907 - la que escribió a Unamuno para quejarse deI agravio de "las plumas"- le dice, expresando una intima reconvención: "Y luego, yo soy de los pocos que han visto en usted al poeta." Para él, ver en Unamuno, en su recia y polifacética personalidad, al poeta, era un relevante testimonio de cordial aprecio y amistad sincera. No podemos dudar, pues, de que le estimó profundamente y fué verdadero anigo suyo.

¿Cómo correspondió Unamuno a estos sentimientos, y cuál fué su juicio sobre la personalidad de Darío? No era Unamuno tan efusi- 
vo en la expresión como su amigo. Pero le escribe largas epístolas tratando de asuntos personales y literarios, que son por sí mismas, para quien conoció al rector de Salamanca, una muestra de singular estimación por el destinatario. En la primera carta - de 16 de abril de 1899- le dice a Rubén: "Lo que yo veo precisamente en usted, a través de lo mejor de lo que de sus obras conozco, es un escritor que quiere decir en castellano cosas que ni en castellano se han pensado nunca, ni pueden hoy en él pensarse." Y al final: "Si, pues, usted se decidiese a visitar este histórico rincón, osario de tradiciones, sabe que en él tiene para acompañarle y servirle de cicerone a un amigo, a un verdadero amigo, que suelo serlo de los que me ganan la simpatía. Y en mí tendrá siempre la amistad sencilla, cordial y franca del vasco, que de serlo hasta los tuétanos se siente satisfecho su afectísimo..." La sinceridad adusta de Unamuno da a sus palabras nucha significación cuando en tales términos se dirige a Dario. En carta del 16 de septiembre del mismo año expresa estos juicios: "De usted me gusta mucho la seriedad, la verdadera seriedad, el esfuerzo por renovarse de continuo. Usted es de los que estudian; se ve en sus trabajos. ¿A quién se le ha ocurrido aquí refrescar la vena de nuestro viejo Cancionero de Baena? Le felicito por ello. Es usted de los que aspiran a comprenderlo todo, de los de mente extensa y hospitalaria, que diría Coll. Eso de mente hospitalaria me ha gustado mucho; es hermosa denominación."

"Ya, al hablarme de usted, me dijo Verdes Montenegro: 'y, sobre todo, es serio'. Para él, que sabe lo que por seriedad yo entiendo, era el mejor elogio que de usted podía hacerme. Sin seriedad no hay genialidad verdadera; no hay más que pose."

Unos años más tarde —en 3 de septiembre de 1904-, después de haber cambiado varias cartas, principia la suya así: "Nada me es más grato que reanudar conversaciones interrumpidas, ni hay palabras que me lleguen más a lo hondo que las paridas por un largo silencio. A usted le recuerdo con frecuencia, depurado, claro está, por la distancia y el tiempo que hace que no le veo. Los que una vez nos encontramos en la vida, donde se cruzan nuestros caminos que, viniendo del infinito al infinito van, seguimos siempre en la vida juntos; cada uno se lleva al otro, y lo mejor del otro, lo que de él pudo hacer propio."

Con ser todo esto bastante expresivo, escrito por una pluma que nunca prodigó amabilidades ni elogios, lo mejor que Unamuno de- 
dicó a Darío fué el conocido artículo a que antes me referí, homenaje al amigo que pasó ya al reino de las sombras, con el cual cree no haber sido siempre justo y bueno. Punzado por el recuerdo de lo que, impropio de su jerarquía moral, indebidamente hizo, escribe Unamuno: "Han pasado más de ocho años de esto; muchas veces esas palabras de noble y triste reproche del pobre Rubén me han sonado dentro del alma, y ahora parece que las oigo salir de su enterramiento, todavía mollar. ¿Fuí con él justo y bueno? No me atrevo a decir que sí.

"Quería alguna palabra de benevolencia para sus esfuerzos de cultura de parte de aquellos con quienes se creía, por encima de diferencias mentales, hermanado en una obra común. Era justo y noble șu deseo."

Se reprocha Unamuno su silencio ante la obra de Darío y dice después: "Era justo; capaz, muy capaz de comprender y de gustar las obras que más se apartaban del sentido y el tono de las suyas; capaz, muy capaz de apreciar los esfuerzos en pro de la cultura que iban por caminos, los al, parecer más opuestos a los suyos. Tenía una amplia universalidad, una profunda liberalidad de criterio. Era benévolo por grandeza de alma, como lo fué antaño Cervantes."

Dice después del hombre: "Aquel hombre, de cuyos vicios tanto se habló y tanto más se fantaseó, era bueno, fundamentalmente bueno, entrañablemente bueno. $Y$ era humilde, cordialmente humilde. Con la grande humildad que, a las veces, se disfraza de soberbia." Y refiriéndose al poeta: "Nadie como él nos tocó en ciertas fibras; nadie como él sutilizó nuestra comprensión poética. Su canto fué como el de la alondra; nos obligó a mirar a un cielo más ancho, por encima de las tapias del jardín patrio en que cantaban, en la enramada, los ruiseñores indígenas. Su canto nos fué un nuevo horizonte, pero no un horizonte para la vista, sino para el oído. Fué como si oyésemos voces misteriosas que venían de más allá de donde a nuestros ojos se juntan el cielo con la tierra, de lo perdido tras la última lontananza."

Para el hombre, para el poeta, para el amigo, tuvo Unamuno palabras sinceras de íntima comprensión y profundo afecto. Hubo, pues, reciprocidad en los sentimientos amistosos y en la estimación literaria. ¿Cómo se explica entonces que cada uno de ellos faltase a los deberes de amistad y consideración respecto del otro, emitiendo en privado juicios que no podían menos de ofenderle? Veamos las "auto- 
referencias", suavizadas quizá por ambos escritores al darlas a la publicidad.

Escribe Unamuno en su artículo sobre Darío: "Con esta lengua que el Demonio nos ha dado a los hombres de letras, dije una vez delante de un compañero de plumá, que a Rubén se le veían las plumas - las del indio- debajo del sombrero; y el que me lo oyó, ni corto ni perezoso, esparció la especie, que llegó a ó́dos de Darío." Por su parte, Darío escribe en el artículo sobre Unamuno: "Un día, en conversación con literatos, dije de Unamuno: un pelotari en Patmos. Le fueron con el chisme, pero él supo comprender la intención, sabiendo que su juego era con las ideas y con los sentires, y que no es desdeñable encontrarse en el mismo terreno con Juan el vidente."

E1 paralelismo de las referencias parece indicar que la frase pronunciada después haya sido una réplica de la anterior. No sé quién faltó primero, aunque sí sospecho que fué Unamuno. $Y$ es natural que su "impertinencia" molestase a Darío, siendo amigos desde hacía varios años. Unamuno, en el artículo necrológico, pretende borrar el efecto ofensivo con estas palabras delicadas: " $F$ Fortuna grande que le conocí y descubrí al hombre, y éste me llevó al poeta! Al indio - lo digo sin asomo de ironía, más bien con pleno acento de reverencia-, al indio que temblaba con todo su ser, como el follaje de un árbol azotado por el viento, ante el misterio." Darío atenúa desde luego, al hacerla pública, la acritud que supone la calificación de "pelotari". Pelotari, jugador vasco de pelota, lo menos intelectual que puede encontrarse entre los paisanos de don Miguel de Unamuno. Mas no creo que el rector de la Universidad de Salamanca quedara satisfecho al ser considerado como un escritor que juega con las ideas en sus libros, como los mozos de su tierra juegan con las pelotas en el frontón, o como unos "artistas", que no quieren trabajar seriamente, juegan en el circo con las botellas o los cuchillos.

Decirle a Darío "indio con plumas" fué una grave ofensa. "Indio" solamente, no. Eran notorios sus caracteres somáticos de indianidad. Y, además, nunca en España hubo menosprecio para los indios de América. Si bien es cierto que colonizadores, mineros y encomenderos españoles abusaron de los indios americanos, no lo es menos que en España se procuró evitar semejante explotación mediante preceptos que, como las famosas Leyes de Indias, consagran y aplican los principios del Derecho natural y de la filosofía cristiana. Forma- 
ron los conquistadores familias mestizas, y en la protección de los indios se llegó hasta el extremo absurdo de que fray Bartolomé de las Casas, el fanático de la indianidad, abogara porque vinieran negros a Amética, en concepto de esclavos, para liberar a los indios de trabajos penosos. Como si el trato que los seres humanos merecen hubiera de graduarse por el color de su piel.

Indios, indolatinos o indoamericanos, siempre hain tenido en España consideración fraternal quienes procedían de este continente. Lo cual no es de extrañar en un país donde ya durante los siglos de la Edad Media convivían amistosamente dentro de las ciudades fronterizas moros, judios y cristianos. La intolerancia y la persecución vinieron después, más por motivos religiosos que por prejuicius raciales.

Decirle "indio con plumas" a Darío fué una grave ofensa. No mucho menor, calificar de pelotari a Unamuno. "El pelotari es usted, pudo contestar don Miguel, que así me devuelve la pelota." Mas, por fortuna, el "incidente" no dejó posos amargos en sus relaciones de amistad. Por el contrario, se hicieron más estrechas y afectuosas. En mi opinión, Darío escribió su primoroso artículo para La Nación, "Unamuno, poeta", como una muestra de cordial reconciliación. Ya lo anuncia en su primera carta posterior a la queja por el agravio recibido, de 9 de octubre de 1907: "Hasta la vista, pues, mi querido amigo, y gracias por su libro de poesía, del cual he de decir en breve lo que todavía no he visto que nadie haya dicho." Unamuno, menos sentimental y expresivo, guardó silencio durante la vida de su amigo y no le rindió el público homenaje a que por sus méritos le consideraba acreedor. Arrepentido, dice en la necrología, tan emocionada, de Darío: “¿Por qué, en vida tuya, amigo, me callé tanto? ¿Qué sé yo!... iqué sé yo !... Es decir, no quiero saberlo. No quiero penetrar en ciertos tristes rincones de nuestro espíritu."

Igual respuesta nos habría dado don Miguel si en vida suya le hubiéramos dicho: ¿por qué habló usted así de su admirado amigo Rubén? "¿Qué sé yo! . . iqué sé yo !... Es decir, no quiero saberlo. No quiero penetrar en ciertos tristes rincones de nuestro espíritu."

Fué realmente una cosa lamentable, de la que he oido interpretaciones poco satisfactorias. Se ha llegado a decir que la "impertinencia" significó una manifestación del orgullo racial propio de los vascos, quienes en la pureza de su sangre ven motivo de engreimiento. Mas nunca me pareció Unamuno tan vasco como él creía ser, y aun 
pienso que su apellido materno (Miguel de Unamuno y Jugo se 1lamaba) autoriza mi suposición al no venir del vascuence, si bien me abstengo de afirmarlo, pues nunca me interesó el estudio de una lengua que, como él decía en carta a Darío (de 12 de enero de 1902), "muere por ley de vida, para provecho de nosotros los vascos, y por no adaptarse a la cultura moderna". Fué don Miguel muy español, paradigma de la cultura hispánica, bien distante del espíritu separatista que alienta ahora a muchos de los políticos nacidos en las provincias vascongadas. Tan español, que yo no puedo imaginármelo desdeñando a Darío por mestizo.

No. Ni un racismo estúpido, ni la envidia, ni otro bajo sentimiento movieron a Unamuno contra Darío. Para mí, el hilo que conduce a la interpretación verdadera nos lo da él, sinceramente, en aquellas palabras de su propia referenciá: "Con esta lengua que el Demonio nos ha dado a los hombres de letras..." Fué, simplemente, un caso de maledicencia, que por desgracia es endémica en los medios literarios. Del mismo modo que los poetas españoles del siglo de oro se disparaban unos contra otros sátiras envenenadas en que la rima daba mayor temple al dardo, muchos escritores modernos se lanzan tajos y mandobles, sólo que en prosa. Sin piedad alguna para el amigo, si a su costa se puede lucir el ingenio. Alguna vez el gran don Miguel se dejó contaminar por el ambiente y fué la víctima Darío.

Pero hayan sido unas u otras las raíces espirituales del "incidente", es lo cierto que a él debemos los amantes de las letras hispánicas dos magníficos escritos, el artículo de Darío y el de Unamuno, que sin disputa pueden considerarse entre los mejores modelos de cincelada prosa y de periodismo literario.

Jerónimo Mallo, University of Iowa, Iowa City, Iowa. 